\title{
Comparisons of biophysical properties and bioactivities of mono-PEGylated endostatin and an endostatin analog
}

Shan Wang ${ }^{1,2,3}$, Yan Fu $\mathrm{Fu}^{1,2,3}$ and Yongzhang Luo 1,2,3*

\begin{abstract}
Background: Endostatin (ES) is a well-established potent endogenous antiangiogenic factor. An ES variant, called zinc-binding protein-ES (ZBP-ES), is clinically available; however, its use is limited by rapid renal clearance and short residence time. PEGylation has been exploited to overcome these shortcomings, and mono-PEGylated ES (called $\mathrm{M}_{2} \mathrm{ES}$ ) as well as mono-PEGylated ZBP-ES (MZBP-ES) are developed in our study. This study aimed to compare the biophysical properties and biological effects of $\mathrm{M}_{2} \mathrm{ES}$ and MZBP-ES to evaluate their druggability.

Methods: Circular dichroism and tryptophan emission fluorescence were used to monitor the conformational changes of $\mathrm{M}_{2} \mathrm{ES}$ and $\mathrm{MZBP}$-ES. Their resistance to trypsin digestion and guanidinium chloride (GdmCl)-induced unfolding was examined by Coomassie staining and tryptophan emission fluorescence, respectively. The biological effects of $\mathrm{M}_{2} \mathrm{ES}$ and MZBP-ES on endothelial cell migration were evaluated using Transwell migration and wound healing assays, and the uptake of $\mathrm{M}_{2} \mathrm{ES}$ and MZBP-ES in endothelial cells was also compared by Western blotting and immunofluorescence.
\end{abstract}

Results: Structural analyses revealed that $\mathrm{M}_{2} \mathrm{ES}$ has a more compact tertiary structure than MZBP-ES. Moreover, $\mathrm{M}_{2} E S$ was more resistant to trypsin digestion and $\mathrm{GdmCl}$-induced unfolding compared with MZBP-ES. In addition, although $\mathrm{M}_{2} \mathrm{ES}$ and MZBP-ES showed comparable levels of inhibiting transwell migration and wound healing of endothelial cells, $\mathrm{M}_{2} \mathrm{ES}$ displayed an increased ability to enter cells compared with MZBP-ES, possibly caused by the enhanced interaction with nucleolin.

Conclusions: $\mathrm{M}_{2} \mathrm{ES}$ has a more compact tertiary structure, is more stable for trypsin digestion and GdmCl-induced unfolding, exhibits increased cellular uptake and shows equivalent inhibitory effects on cell migration relative to $M Z B P-E S$, indicating that $\mathrm{M}_{2} E S$ is a more promising candidate for anticancer drug development compared with MZBP-ES.

Keywords: Endostatin, PEGylation, Antiangiogenic therapy, Drug design, Zinc-binding protein-endostatin

\section{Background}

Angiogenesis, the formation of new capillaries from preexisting blood vessels, is vital for both physiologic and pathologic conditions. As one of the hallmarks of cancer [1], the process of angiogenesis is exquisitely regulated by a variety of activators and inhibitors [2, 3]. These proangiogenic and anti-angiogenic factors constitute a tightly

\footnotetext{
*Correspondence: yluo@tsinghua.edu.cn

${ }^{3}$ Cancer Biology Laboratory, School of Life Sciences, Tsinghua University, Beijing 100084, P. R. China

Full list of author information is available at the end of the article
}

controlled angiogenic balance. Among them, one of the first identified endogenous factors with anti-angiogenic activities was endostatin (ES) [4]. ES, a $22 \mathrm{kD}$ C-terminal fragment of collagen XVIII, can significantly retard tumor growth by targeting endothelial cells in mouse models [5] when assessed by proliferation, migration, tube formation, and numerous signaling pathways. The clinical trials of ES in the United States failed due to insufficient efficacy and problems in the production and formulation [5]. However, mutagenesis of ES by the linkage of MGGSH$\mathrm{HHHH}$ to the $\mathrm{N}$ terminus stabilizes $\mathrm{ES}$ and has made it 
successfully clinically available [5]. This ES variant, also known as the zinc-binding protein-endostatin (ZBP-ES), was approved by the China Food and Drug Administration (CFDA) to treat non-small cell lung cancer (NSCLC) patients in China in 2005 [6]. As a widely used anticancer drug in China, ZBP-ES has exhibited beneficial therapeutic effects [7-9]. A meta-analysis of clinical data, involving 1953 NSCLC patients, demonstrated that ZBP-ES co-treatment significantly improved the overall response rate and disease control rate of patients who underwent platinum-based doublet chemotherapy by 14.7 and 13.5\%, respectively [6]. In another study, the endpoints of progression-free survival (PFS) and overall survival (OS) were evaluated in a total of 110 patients with metastatic melanomas [8]. Significant improvements were observed in favor of the ZBP-ES plus dacarbazine arm compared with the placebo plus dacarbazine arm (PFS, 4.5 vs. 1.5 months; OS, 12.0 vs. 8.0 months). However, hindered by its relatively rapid renal clearance and short circulation half-life in vivo [10], ZBP-ES was recommended to be taken on a daily basis in clinic.

PEGylation, the process of covalent attachment of polyethylene glycol (PEG) to the proteins or peptides, can overcome the short half-life problem. PEGylation masks the surface of the proteins and increases their molecular size, therefore protecting them from protease digestion and renal filtration, while at the same time increasing the protein's stability and residence time in vivo [11]. The applicability and safety of this strategy have been well documented, and PEGylated proteins have been used in clinics for years. Our group and our partners have developed a second generation of ES by conjugation of a PEG molecule to the $\mathrm{N}$ terminus of wild-type ES, which is also known as $\mathrm{M}_{2} \mathrm{ES}$, and have tested its safety and efficacy in preclinical and clinical studies $[12,13] . M_{2} E S$ showed a broad spectrum of antitumor activities in several types of tumors (data to be published) and was well tolerated in rhesus monkeys [12]. Furthermore, in the phase I trial, $\mathrm{M}_{2} \mathrm{ES}$ was well tolerated in pancreatic adenocarcinoma patients when concurrently administered with gemcitabine [13]. Other groups have also generated mono-PEGylated ZBPES and examined its potency in animal models $[14,15]$.

The objective of this study was to comprehensively compare both the biophysical properties and biological activities of $\mathrm{M}_{2} \mathrm{ES}$ and mono-PEGylated ZBP-ES (MZBP$E S)$, and therefore provide a basis for better understanding the druggability and bioactivities of PEGylated ES variants.

\section{Methods}

\section{Proteins, antibodies, and cell culture}

The recombinant proteins used in this study were provided by Protgen Co., Ltd. (Beijing, China). ES and
ZBP-ES were expressed in E. coli, refolded into native forms and purified. The N-terminal site-directed monoPEGylation was conducted by addition of $20 \mathrm{mmol} / \mathrm{L}$ $\mathrm{NaBH}_{3} \mathrm{CN}$ and incubating the PEG2000 and proteins (PEG2000:protein $=1.5: 1$ ) at room temperature for more than $2 \mathrm{~h}$, followed by purification.

We purchased primary antibodies against extracellular regulated protein kinases (Erk), phosphor-Erk, glyceraldehyde 3-phosphate dehydrogenase (GAPDH) (Santa Cruz Biotechnology, Santa Cruz, CA, USA), PEG (Abcam, Cambridge, UK), and turbo green fluorescent protein (tGFP) (OriGene, Rockville, MD, USA). Anti-ES antibody was from our lab stock.

Human microvascular endothelial cells (HMECs) were from our lab stock and cultured in Dulbecco's Modified Eagle Medium (DMEM) containing 10\% fetal bovine serum (Hyclone, Logan, UT, USA).

\section{Circular dichroism (CD)}

The far-ultraviolet (UV) CD spectra were obtained by a Chirascan $^{\text {TM }}$-plus CD Spectrometer (Applied photophysics, Surrey, UK). ES or its variants were diluted in $5 \mathrm{mmol} / \mathrm{L}$ Tris- $\mathrm{HCl}, \mathrm{pH} 7.4$, to a final concentration of $10 \mu \mathrm{mol} / \mathrm{L}$. For each protein, data were recorded three times and corrected by subtracting the baseline spectrum of the buffer.

\section{Tryptophan emission fluorescence}

Tryptophan emission fluorescence is a good probe to monitor the subtle tertiary structural changes of ES [16]. Proteins $(1 \mu \mathrm{mol} / \mathrm{L})$ in Tris buffer were measured as previously described [17].

\section{Proteolysis assay}

ES or its variants $(0.5 \mathrm{mg} / \mathrm{mL})$ were incubated with trypsin $(0.2 \mathrm{mg} / \mathrm{mL})$ in phosphate buffer saline (PBS) buffer ( $\mathrm{pH} 7.4)$ at $37^{\circ} \mathrm{C}$ [18]. At each indicated time point, reaction solutions were quickly removed and mixed with the sodium dodecyl sulfate-polyacrylamide gel electrophoresis (SDS-PAGE) loading buffer to stop the trypsin digestion reactions. The samples were subsequently subjected to SDS-PAGE and stained with the Coomassie dye.

\section{Guanidinium chloride ( $\mathrm{GdmCl}$ )-induced unfolding}

ES or its variants $(0.8 \mu \mathrm{mol} / \mathrm{L})$ were incubated in $5 \mathrm{mmol} / \mathrm{L}$ Tris- $\mathrm{HCl}, \mathrm{pH}$ 7.4, containing $\mathrm{GdmCl}$ concentrations ranging from 0 to $6 \mathrm{~mol} / \mathrm{L}$. After incubation for $24 \mathrm{~h}$ at room temperature, $\mathrm{GdmCl}$-induced denaturation was monitored by the tryptophan emission fluorescence intensity at $318 \mathrm{~nm}[5,19]$. Data were normalized by subtracting the baseline fluorescence intensity of the buffer. The linear extrapolation method was used to evaluate the value of the free change energy in the absence of the denaturant $\mathrm{GdmCl}\left(\Delta \mathrm{G}_{\mathrm{N}-\mathrm{U}}^{\mathrm{o}}\right)$, the apparent slope of the 
plots (m), and the concentration of $\mathrm{GdmCl}$ at the midpoint of the unfolding transition $\left(\mathrm{C}_{\mathrm{m}}\right)$ as described by Santoro and Bolen [20].

\section{In vitro protein-protein interactions}

The nucleolin-tGFP plasmid was transfected into HMECs. Nucleolin-tGFP proteins were immunoprecipitated following the procedure described in our previous study [21]. Subsequently, ES or its variants were incubated with the nucleolin-tGFP beads for $1 \mathrm{~h}$ at $4{ }^{\circ} \mathrm{C}$. After washing with the lysis buffer $(150 \mathrm{mmol} / \mathrm{L}$ Tris, $50 \mathrm{mmol} / \mathrm{L}$ sodium chloride, $1 \% \mathrm{NP} 40$, protease inhibitor mixture, $\mathrm{pH}$ 7.4), the bead-bound proteins were subjected to Western blotting.

\section{Internalization assay}

As previously described [22], HMECs were treated with $5 \mu \mathrm{g} / \mathrm{mL}$ ES or its variants for $1 \mathrm{~h}$. Subsequently, cells were washed with acidic buffer ( $\mathrm{pH}$ 3.5) and ice-cold PBS to remove cell surface-binding proteins. The amount of internalized proteins was examined by Western blotting or immunofluorescence.

\section{Western blotting}

Protein samples were separated by SDS-PAGE and transferred to a polyvinylidene difluoride (PVDF) membrane. After blocking for $1 \mathrm{~h}$ at room temperature, the membrane was incubated with the indicated primary antibodies overnight and then to the corresponding horseradish peroxidase (HRP)-conjugated goatanti-mouse or goat-anti-rabbit secondary antibodies for $1 \mathrm{~h}$. The enhanced chemiluminescent substrate was added to the blot, and reactive bands were detected.

\section{Immunofluorescence}

Cells were seeded directly on coverslips, fixed, and stained. After blocking with 5\% goat serum, cells were incubated with the indicated primary antibodies and fluorescein isothiocyanate (FITC)-labeled secondary antibodies. The nucleus was stained with 4',6-diamidino-2-phenylindole (DAPI). Images were captured using a Nikon A1 confocal microscope (Nikon Corporation, Tokyo, Japan).

\section{Transwell migration and wound healing}

Transwell migration and wound healing assays were conducted as previously described [22]. Cells were treated with the indicated proteins for 6 and $48 \mathrm{~h}$ at $37{ }^{\circ} \mathrm{C}$, respectively. All experiments were repeated twice.

\section{Statistical analyses}

All data from the experiments were presented as means \pm standard deviations (SDs). Differences between two groups were calculated by GraphPad (GraphPad Software, San Diego, CA, USA), and considered significant if the $P$ value was $<0.05$ using a two-tailed Student's $t$ test.

\section{Results}

\section{Structural analyses}

The schematic diagram shows the sequence of ES, ZBPES, $M_{2} E S$, and MZBP-ES (Fig. 1a). The purity of these proteins is shown in Fig. 1b. The proteins were tested for secondary and tertiary structures using $C D$ and tryptophan emission fluorescence. The CD spectra results revealed that no obvious change in the secondary structure was observed between ES and ZBP-ES, whereas slight differences were observed between $\mathrm{M}_{2} \mathrm{ES}$ and MZBP-ES (Fig. 1c). The maximal Trp fluorescence emission wavelengths $\left(\lambda_{\max }\right)$ of all the ES variants were approximately $318 \mathrm{~nm}$ (Fig. 1d), indicating a relatively stable core structure of ES variants. However, the fluorescence intensities of $E S$ and $M_{2} E S$ were higher than those of ZBP-ES and MZBP-ES, respectively, implying that the tertiary structure of ES is more compact than that of ZBP-ES and that the tertiary structure of $\mathrm{M}_{2} \mathrm{ES}$ is more compact than that of MZBP-ES.

Taken together, N-terminal modifications do not affect the core structure of ES, whereas the tertiary structure of $\mathrm{M}_{2} \mathrm{ES}$ is more compact than that of MZBP-ES.

\section{Protease digestion}

To identify the stability of ES variants, trypsin was incubated with ES variants for the indicated time periods. ES was quickly digested within 20 min, whereas ZBPES was not totally digested until $4 \mathrm{~h}$ (Fig. 2a). PEGylated proteins were overall more resistant to trypsin digestion compared with intact proteins. Interestingly, after incubation for $6 \mathrm{~h}$, the residual amount of full-length $\mathrm{M}_{2} \mathrm{ES}$ was larger than that of MZBP-ES. Quantitative results showed that the initial reaction rate was $0.026 \mathrm{mg} /$ (mL.min) for $\mathrm{M}_{2} \mathrm{ES}$ and $0.037 \mathrm{mg} /(\mathrm{mL} \cdot \mathrm{min})$ for MZBPES. These results showed that $\mathrm{M}_{2} \mathrm{ES}$ was more resistant to trypsin digestion than MZBP-ES.

\section{GdmCl-induced unfolding}

$\mathrm{GdmCl}$-induced unfolding was used to detect the structural stability and unfolding cooperativity of ES variants. Slight changes were observed between the unfolding curves of ES and ZBP-ES (Fig. 2b, upper panel). These two proteins had a similar $C_{m}$ value, whereas the modified ES exhibited lower values of $\Delta \mathrm{G}_{\mathrm{N}-\mathrm{U}}^{\mathrm{O}}$ and $\mathrm{m}$ (Table 1). Moreover, the unfolding curve of $\mathrm{M}_{2} \mathrm{ES}$ had slight shifts towards higher $\mathrm{GdmCl}$ concentrations compared with that of MZBP-ES (Fig. 2b, lower panel), with increases in $\Delta \mathrm{G}_{\mathrm{N}-\mathrm{U}}^{\mathrm{o}}, \mathrm{m}$, and $\mathrm{C}_{\mathrm{m}}$ (Table 1). These results showed that 


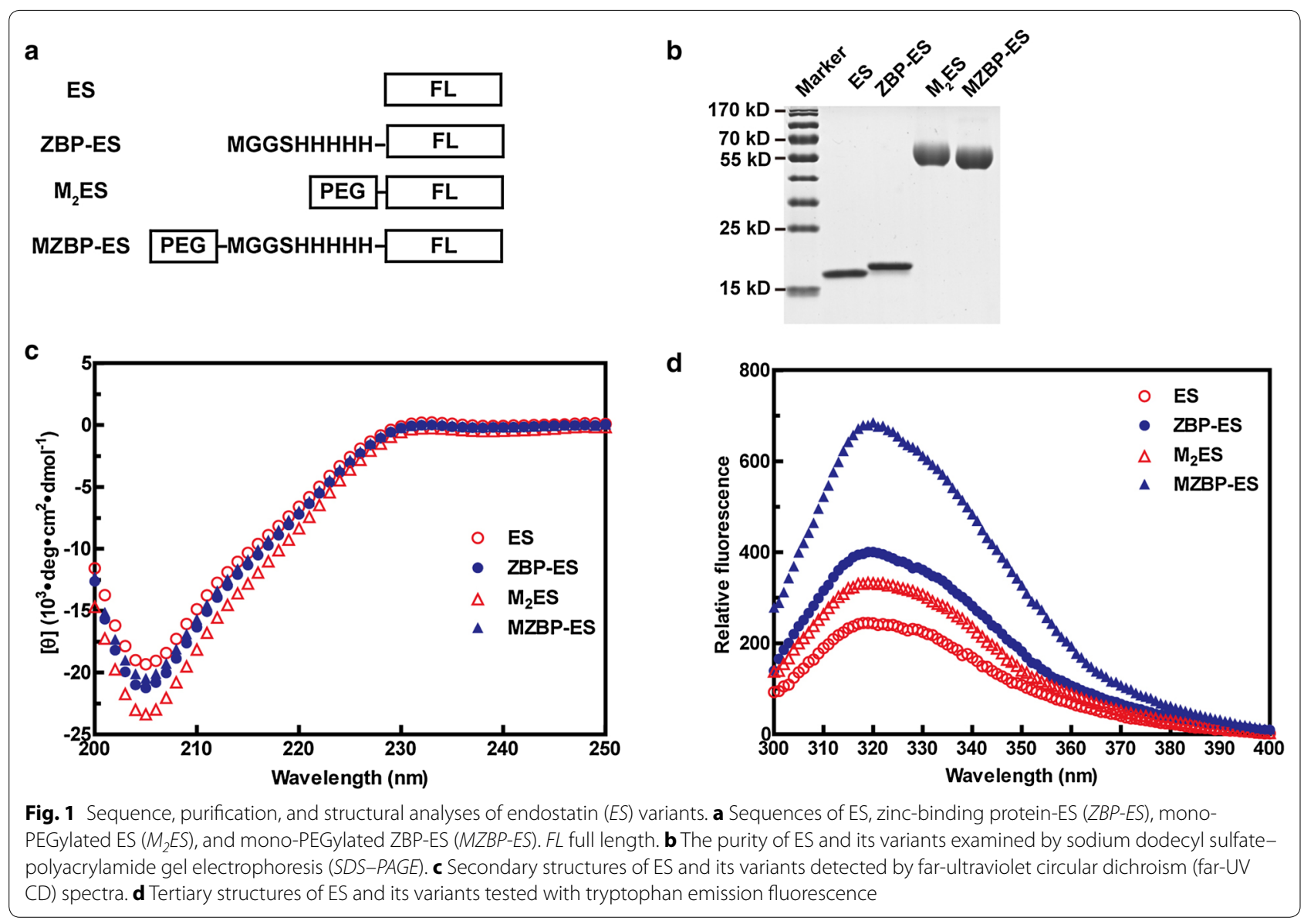

both the structural stability and unfolding cooperativity of $\mathrm{M}_{2} \mathrm{ES}$ were better than those of MZBP-ES (Fig. 2c).

\section{Biological activities}

We next investigated the effects of ES variants on endothelial cell activities. ES and its variants significantly reduced endothelial cell migration, and PEGylated proteins were more efficient compared with intact proteins (Fig. 3a, b). In the Transwell assay, $\mathrm{M}_{2} \mathrm{ES}$ and MZBP-ES inhibited endothelial cell migration to an equivalent extent. The wound healing scratch results showed that $\mathrm{M}_{2} \mathrm{ES}$ was slightly more potent than MZBP-ES in retarding wound healing (Fig. 3c).

ES was shown to bind to the vascular endothelial growth factor receptor 2 (VEGFR2) on the surface of endothelial cells and disrupt vascular endothelial growth factor (VEGF)-induced activation of mitogenactivated protein kinase/extracellular regulated protein kinases (MAPK/Erk) [23]. All ES variants inhibited Erk phosphorylation (Fig. 3d). ZBP-ES was more potent in reducing Erk activation compared with ES, whereas the blockage effect of $\mathrm{M}_{2} \mathrm{ES}$ was more potent than that of MZBP-ES.
In summary, $\mathrm{M}_{2} \mathrm{ES}$ and MZBP-ES had comparable effects on the inhibition of cell migration, whereas $\mathrm{M}_{2} \mathrm{ES}$ was more efficient in disrupting Erk activation.

\section{Internalization by endothelial cells and interactions with cell surface receptors}

Internalization is important, if not critical, for the biological functions of ES [24]. Increasing the uptake of ES via the addition of cholesterol chelating agents [22] or engineering a peptide to its $\mathrm{N}$ terminus [25] dramatically enhanced the therapeutic efficacy of ES. We determined the uptake of ES and its variants by HMECs and found that ZBP-ES was more efficient in entering the cells than ES (Fig. 4a), which validates the data from our previous study [16]. Intriguingly, more $\mathrm{M}_{2} \mathrm{ES}$ proteins accumulated in the cells than MZBP-ES (Fig. 4a). Consistent results were obtained by immunofluorescence (Fig. 4b).

Nucleolin is a functional receptor of ES and participates in the ES internalization process [26]; therefore, we explored whether the distinction of ES variant internalization was attributed to different binding affinities to nucleolin. Consistent with the internalization results (Fig. 4a, b), ES showed weaker interaction with nucleolin 


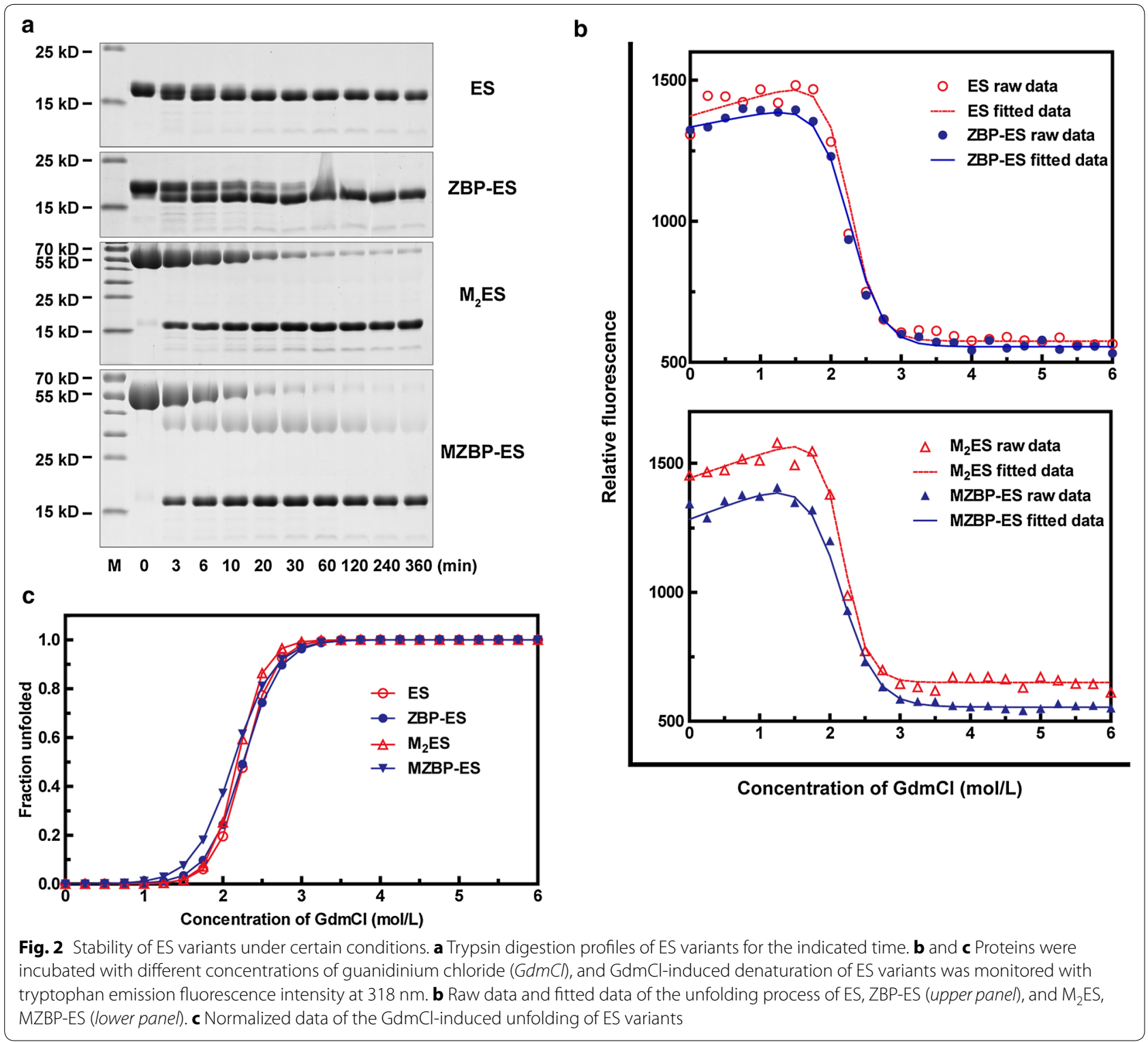

Table 1 Parameters of the $\mathrm{GdmCl}$-induced unfolding of ES variants

\begin{tabular}{llll}
\hline Protein & $\mathbf{\Delta} \mathbf{G}_{\mathbf{N}-\mathbf{U}}^{\mathbf{o}}(\mathbf{k J} / \mathbf{m o l})$ & $\mathbf{m}\left(\mathbf{k J} \cdot \mathbf{L} / \mathbf{m o l}^{\mathbf{2}}\right)$ & $\mathbf{C}_{\mathbf{m}}(\mathbf{m o l} / \mathbf{L})$ \\
\hline ES & 29.23 & 12.88 & 2.27 \\
ZBP-ES & 24.16 & 10.70 & 2.26 \\
M $_{2}$ ES & 31.27 & 14.31 & 2.18 \\
MZBP-ES & 20.57 & 9.65 & 2.13 \\
\hline
\end{tabular}

$\mathrm{GdmCl}$ guanidinium chloride, $\Delta G_{N-U}^{o}$ the free change energy in the absence of $\mathrm{GdmCl}, m$ the apparent $\mathrm{m}$ value defined by the linear extrapolation model, $C_{m}$ the concentration of $\mathrm{GdmCl}$ at the midpoint of the unfolding transition, ES endostatin, ZBP-ES zinc-binding protein-ES, $M_{2} E S$ mono-PEGylated ES, MZBP-ES mono-PEGylated ZBP-ES than ZBP-ES, whereas $\mathrm{M}_{2} \mathrm{ES}$ showed increased interaction with nucleolin compared with MZBP-ES (Fig. 4c).

Collectively, $\mathrm{M}_{2} \mathrm{ES}$ exhibited an increased cellular uptake than MZBP-ES, possibly caused by the enhanced interaction with its functional receptor nucleolin.

\section{Discussion}

In this study, we demonstrate that $\mathrm{M}_{2} \mathrm{ES}$ not only has a more compact tertiary structure than MZBP-ES but also exhibits more resistance to trypsin digestion and $\mathrm{GdmCl}-$ induced unfolding. Although $\mathrm{M}_{2} \mathrm{ES}$ shows comparable inhibitory effects on endothelial cell migration and 


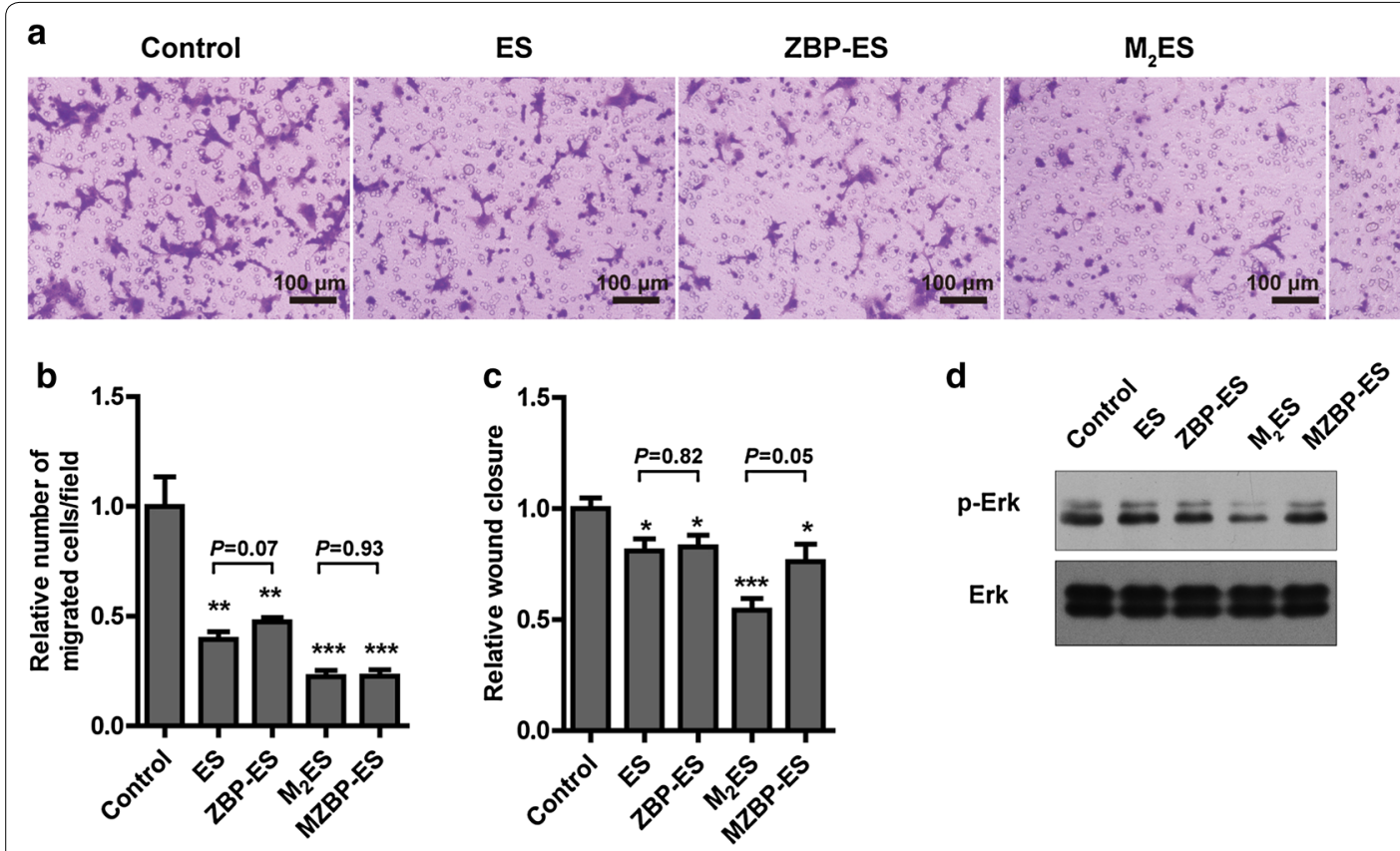

Fig. 3 Biological activities of ES variants. $\mathbf{a}$ and $\mathbf{b}$ Representative images and quantified results of the Tranwell migration assay for endothelial cells. Human microvascular endothelial cells (HMECs) were seeded into the upper well of the Boyden chamber and treated with the indicated proteins for $6 \mathrm{~h}$. Cells were stained with crystal violet, photographed, and counted. c In the wound healing assay, the HMEC monolayer was scratched and cultured in serum-free media in the absence or presence of the indicated proteins for $48 \mathrm{~h}$. Cells were photographed at 0 and $48 \mathrm{~h}$, respectively, and the relative wound closure was quantified. $\mathbf{d}$ Erk phosphorylation of ES variant treatments examined by Western blotting. Error bars indicate standard deviations (SDs). ${ }^{*} P<0.05,{ }^{* *} P<0.01,{ }^{* *} P<0.001$, vs. control

wound healing compared with MZBP-ES, $\mathrm{M}_{2} \mathrm{ES}$ is more efficient in entering the cells than MZBP-ES, possibly due to enhanced interaction with its functional receptor nucleolin.

$\mathrm{M}_{2} \mathrm{ES}$ is more stable towards trypsin digestion than MZBP-ES (Fig. 2a). Our previous study revealed that the endostatin digestion process contains two stages: cleavage of the first four residues (HSHR) during the first stage and further digestion of the dominant product in the second stage [18]. We therefore supposed that the PEG molecule in $\mathrm{M}_{2} \mathrm{ES}$ masks the HSHR residues and therefore protects it from degradation by trypsin, whereas the PEG molecule of MZBP-ES covers the MGGSHHHHH part, instead of the first four residues, making MZBP-ES more susceptible to protease digestion.
Endostatin is well established as an antiangiogenic factor; therefore, our study focused on the direct impacts of ES and PEGylated ES on endothelial cells. However, endothelial cells are not the only target of ES. Our recent study showed that adipocytes were also targeted by ES. ES can inhibit adipogenesis and dietaryinduced obesity and its related metabolic disorders, including glucose intolerance, insulin resistance, and hepatic steatosis [27]. Although both intensive and extensive researches were performed on ES, and it appeared that there was not much progress on this protein, this new discovery suggests a potential expanded application of ES for the treatment of obesity. Moreover, this discovery opens new avenues for this protein and indicates that this is only the beginning. 


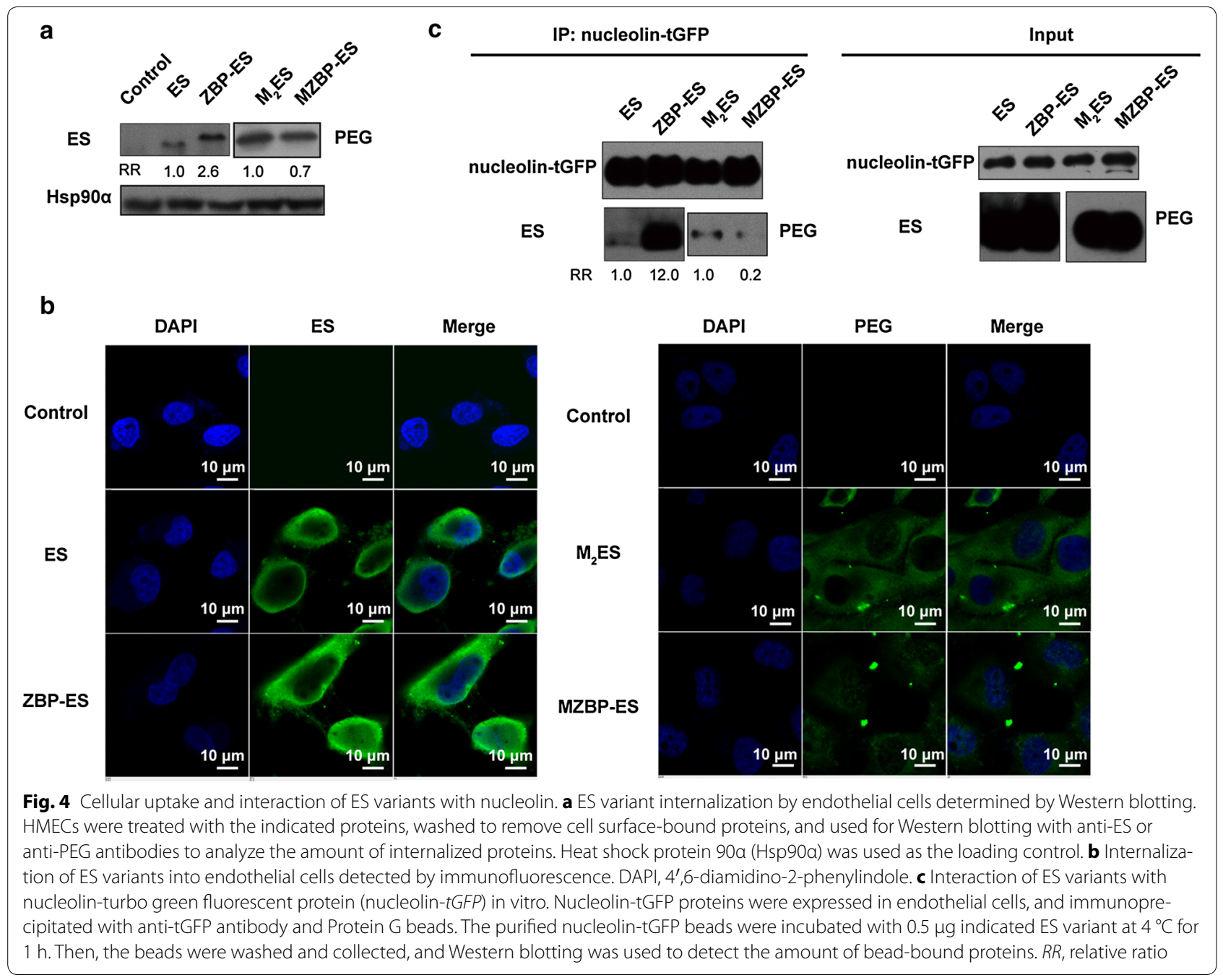

\section{Conclusions}

Collectively, these findings suggest that $\mathrm{M}_{2} \mathrm{ES}$ is a more suitable drug candidate in comparison with MZBP-ES and provides a basis for further endostatin-based drug development.

\section{Authors' contributions}

SW designed the research, carried out experiments, interpreted data, and wrote the manuscript. YF participated in data analysis and interpretation, as well as administration and grant support. YL supervised the study, interpreted data, and wrote the manuscript. All authors read and approved the final manuscript.

\section{Author details}

${ }^{1}$ The National Engineering Laboratory for Anti-tumor Protein Therapeutics, School of Life Sciences, Tsinghua University, Beijing 100084, P. R. China. ${ }^{2}$ Beijing Key Laboratory for Protein Therapeutics, School of Life Sciences, Tsinghua University, Beijing 100084, P. R. China. ${ }^{3}$ Cancer Biology Laboratory, Schoo of Life Sciences, Tsinghua University, Beijing 100084, P. R. China.

\section{Acknowledgements}

We thank Shaogin Zhang (Tsinghua University) for the circular dichroism experiments and all the Luo laboratory members for their insightful discussions.
YL was supported by the General Programs of the National Natural Science Foundation of China (No. 81171998, 81472667, and 81461148021), the National Science and Technology Major Project for "Major New Drugs Innovation and Development" (No. 2013ZX09509103). YF was supported by the General Programs of the National Natural Science Foundation of China (No. 81272529).

\section{Competing interests}

The authors declare that they have no competing interests.

Received: 14 September 2015 Accepted: 25 November 2015

Published online: 20 January 2016

\section{References}

1. Hanahan D, Weinberg RA. Hallmarks of cancer: the next generation. Cell. 2011;144(5):646-74. doi:10.1016/j.cell.2011.02.013.

2. Stacker SA, Achen MG. The VEGF signaling pathway in cancer: the road ahead. Chin J Cancer. 2013;32(6):297-302. doi:10.5732/cjc.012.10319.

3. Yan L. Molecular targeted agents-where we are and where we are going. Chin J Cancer. 2013;32(5):225-32. doi:10.5732/cjc.013.10051. 
4. O'Reilly MS, Boehm T, Shing Y, Fukai N, Vasios G, Lane WS, et al. Endostatin: an endogenous inhibitor of angiogenesis and tumor growth. Cell. 1997:88(2):277-85.

5. Fu Y, Tang H, Huang $Y$, Song $N$, Luo Y. Unraveling the mysteries of endostatin. IUBMB Life. 2009;61(6):613-26. doi:10.1002/iub.215.

6. Rong B, Yang S, Li W, Zhang W, Ming Z. Systematic review and metaanalysis of Endostar (rh-endostatin) combined with chemotherapy versus chemotherapy alone for treating advanced non-small cell lung cancer. World J Surg Oncol. 2012;10:170. doi:10.1186/1477-7819-10-170.

7. Han B, Xiu Q, Wang H, Shen J, Gu A, Luo Y, et al. A multicenter, randomized, double-blind, placebo-controlled study to evaluate the efficacy of paclitaxel-carboplatin alone or with endostar for advanced nonsmall cell lung cancer. J Thorac Oncol. 2011;6(6):1104-9. doi:10.1097/ JTO.0b013e3182166b6b.

8. Cui C, Mao L, Chi Z, Si L, Sheng X, Kong Y, et al. A phase II, randomized, double-blind, placebo-controlled multicenter trial of endostar in patients with metastatic melanoma. Mol Ther. 2013;21(7):1456-63. doi:10.1038/ mt.2013.79.

9. Sun Y, Wang JW, Liu YY, Yu QT, Zhang YP, Li K, et al. Long-term results of a randomized, double-blind, and placebo-controlled phase III trial: endostar (rh-endostatin) versus placebo in combination with vinorelbine and cisplatin in advanced non-small cell lung cancer. Thorac Cancer. 2013;4(4):440-8. doi:10.1111/1759-7714.12050.

10. Lee SH, Jeung IC, Park TW, Lee K, Lee DG, Cho YL, et al. Extension of the in vivo half-life of endostatin and its improved anti-tumor activities upon fusion to a humanized antibody against tumor-associated glycoprotein 72 in a mouse model of human colorectal carcinoma. Oncotarget. 2015;6(9):7182-94.

11. Harris JM, Chess RB. Effect of pegylation on pharmaceuticals. Nat Rev Drug Discov. 2003;2(3):214-21. doi:10.1038/nrd1033.

12. Guo L, Geng X, Chen Y, Qi F, Liu L, Miao Y, et al. Pre-clinical toxicokinetics and safety study of M2ES, a PEGylated recombinant human endostatin, in rhesus monkeys. Regul Toxicol Pharmacol. 2014;69(3):512-23. doi:10.1016/j.yrtph.2014.05.019.

13. Chen Y, Du Y, Li P, Wu F, Fu Y, Li Z, et al. Phase I trial of MES, a novel polyethylene glycosylated recombinant human endostatin, plus gemcitabine in advanced pancreatic cancer. Mol Clin Oncol. 2014;2(4):586-90. doi:10.3892/mco.2014.271.

14. Nie $Y$, Zhang $X$, Wang $X$, Chen J. Preparation and stability of N-terminal mono-PEGylated recombinant human endostatin. Bioconjug Chem. 2006;17(4):995-9. doi:10.1021/bc050355d.

15. Tong Y, Zhong K, Tian H, Gao X, Xu X, Yin X, et al. Characterization of a monoPEG20000-Endostar. Int J Biol Macromol. 2010;46(3):331-6. doi:10.1016/j.ijbiomac.2010.01.017.

16. Fu Y, Luo Y. The N-terminal integrity is critical for the stability and biological functions of endostatin. Biochemistry. 2010;49(30):6420-9. doi:10.1021/bi100489x.
17. Wang S, Lu XA, Liu P, Fu Y, Jia L, Zhan S, et al. Endostatin has ATPase activity, which mediates its anti-angiogenic and anti-tumor activities. Mol Cancer Ther. 2015;14(5):1 192-201. doi:10.1158/1535-7163.MCT-14-0836.

18. Han Q, Fu Y, Zhou H, He Y, Luo Y. Contributions of Zn(II)-binding to the structural stability of endostatin. FEBS Lett. 2007;581(16):3027-32. doi:10.1016/j.febslet.2007.05.058.

19. Li B, Wu X, Zhou H, Chen Q, Luo Y. Acid-induced unfolding mechanism of recombinant human endostatin. Biochemistry. 2004;43(9):2550-7. doi:10.1021/bi0357863.

20. Santoro MM, Bolen DW. Unfolding free energy changes determined by the linear extrapolation method. 1. Unfolding of phenylmethanesulfonyl alpha-chymotrypsin using different denaturants. Biochemistry. 1988;27(21):8063-8.

21. Fu Y, Chen Y, Luo X, Liang Y, Shi H, Gao L, et al. The heparin binding motif of endostatin mediates its interaction with receptor nucleolin. Biochemistry. 2009;48(49):11655-63. doi:10.1021/bi901265z.

22. Chen Y, Wang S, Lu X, Zhang H, Fu Y, Luo Y. Cholesterol sequestration by nystatin enhances the uptake and activity of endostatin in endothelium via regulating distinct endocytic pathways. Blood. 2011;117(23):6392403. doi:10.1182/blood-2010-12-322867.

23. Kim YM, Hwang S, Pyun BJ, Kim TY, Lee ST, Gho YS, et al. Endostatin blocks vascular endothelial growth factor-mediated signaling via direct interaction with KDR/FIk-1. J Biol Chem. 2002;277(31):27872-9. doi:10.1074/jbc. M202771200.

24. Shi H, Huang $Y$, Zhou $H$, Song $X$, Yuan S, Fu Y, et al. Nucleolin is a receptor that mediates antiangiogenic and antitumor activity of endostatin. Blood. 2007;110(8):2899-906. doi:10.1182/blood-2007-01-064428.

25. Lim J, Duong T, Lee G, Seong BL, El-Rifai W, Ruley HE, et al. The effect of intracellular protein delivery on the anti-tumor activity of recombinant human endostatin. Biomaterials. 2013;34(26):6261-71. doi:10.1016/j. biomaterials.2013.05.011.

26. Song N, Ding Y, Zhuo W, He T, Fu Z, Chen Y, et al. The nuclear translocation of endostatin is mediated by its receptor nucleolin in endothelial cells. Angiogenesis. 2012;15(4):697-711. doi:10.1007/s10456-012-9284-y.

27. Wang H, Chen Y, Lu XA, Liu G, Fu Y, Luo Y. Endostatin prevents dietaryinduced obesity by inhibiting adipogenesis and angiogenesis. Diabetes. 2015;64(7):2442-56. doi:10.2337/db14-0528.

\section{Submit your next manuscript to BioMed Central and we will help you at every step:}

- We accept pre-submission inquiries

- Our selector tool helps you to find the most relevant journal

- We provide round the clock customer support

- Convenient online submission

- Thorough peer review

- Inclusion in PubMed and all major indexing services

- Maximum visibility for your research

Submit your manuscript at www.biomedcentral.com/submit

\section{() BiolMed Central}

